\title{
Inhibitory Potential of Dietary Phytocompounds of Nigella sativa against Key Targets of Novel Coronavirus (COVID-19)
}

\author{
Pratibha Pandey ${ }^{1, \star}$, Fahad Khan ${ }^{1}$, Avijit Mazumder², Ansh Kumar Rana1, Yashvi Srivastava1 \\ 'Department of Biotechnology, Noida Institute of Engineering and Technology, Greater Noida, INDIA. \\ ${ }^{2}$ Noida institute of Engineering and Technology (Pharmacy Institute), Greater Noida, INDIA.
}

\begin{abstract}
Aim/Background: Dietary factors have shown important role in the rapid management of several human ailments including viral infections. Since ancient times, constituents of Nigella sativa seeds have been utilized as food preservatives with significant medicinal benefits in Unani and Ayurveda practices. Nigella sativa (Black seed) has presented significant therapeutic potential against several disorders and known to have numerous biological activities (such as antibacterial, antiviral and anti-inflammatory). Nigella plant has shown significant potential in the reduction of viral load as well as in enhancing immunity. Materials and Methods: Our study enlightens the inhibitory role of phytocompounds of Nigella sativa against various key targets of coronavirus through in silico approaches including molecular docking using several software's such as AUTO DOCK 4.2 and PATCH DOCK. Results: Thus in this study, we have elucidated the potential of best reported phytocompounds of Nigella sativa as potent inhibitors of COVID-19. We have mainly focused our study towards inhibiting four different targets in CoVs. Molecular docking was performed between 10 potent compounds to identify best potential inhibitor which could inhibit the viral attachment and replication. Nigellone have shown the most significant inhibitory potential (with Binding energy of -5.48) against all the four crucial targets of coronavirus. Conclusion: Further, in vitro experiments are needed to validate the efficacy of Nigellone as a potential lead compound for the management of COVID-19 disease.
\end{abstract}

Key words: COVID-19, Nigella sativa, Molecular Docking, Dietary Phytocompounds, AutoDock.

\section{INTRODUCTION}

COVID-19 (Novel coronavirus) has been reported in December 2019 in Hubei, China. ${ }^{1}$ Coronavirus infection is associated with numerous disorder and infections in the digestive tract and respiratory tract. $^{2}$ WHO (World Health Organization) declared COVID-19 as pandemic on March 11, 2020, which resulted in severe mortality globally. ${ }^{3}$ Due to the dreadful situation caused by COVID-19, there is an indispensable need to find potent targeted therapeutic agents which could inhibit the COVID-19 progression. Structural details of coronavirus have presented the potential of several targets like 3C-like protease, spike protein and papain-like protease for drug development. Several researches reported the fact that, coronavirus spike protein binds to the host cells via ACE2 (entry receptor), PAMP (pathogen-associated molecular patterns) or viral RNAs, gets recognized by the pattern recognition receptors such as TLR (Toll like receptors). ${ }^{4}$ Viral polypeptide onto functional proteins is processed by Coronavirus papain like protease (PLpro) protein acts as deubiquitinating enzyme that can reduce anti-viral response of host by expropriate the ubiquitin pathway (Ub system). ${ }^{5}$ Natural compounds have exhibited significant antiviral potential in
Submission Date: 07-08-2020; Revision Date: 08-10-2020; Accepted Date: 29-12-2020

DOI: 10.5530/ijper.55.1.21 Correspondence: Dr. Fahad Khan Assistant Professor, Department of Biotechnology, Noida Institute of Engineering and Technology, Greater Noida, INDIA.

Phone: +91 8923580628

E-mail: fahadintegralian@ gmail.com

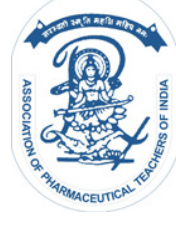

www.ijper.org 
past years and therefore we have focused our research towards exploiting the potential of some potent phytocompounds of Nigella sativa which has previously been reported with significant medicinal benefits against numerous viral diseases. ${ }^{6}$

We have included four different targets of coronavirus towards finding better therapeutic agents for the treatment of COVID-19 disease. Although there are several reported research that has explained the inhibitory potential of natural products against Coronavirus protein. ${ }^{7,8}$ However this study would be the first study that has elucidated the inhibitory potential of phytocompounds of Nigella sativa against these four crucial targets of coronavirus which could pave a strong path towards drug development for COVID-19.

\section{MATERIALS AND METHODS}

\section{Target Structure Preparation for Docking}

In this study, we have selected four different targets (Table 1) responsible for the progression of COVID19 disease including 6VSB Prefusion 2019-nCoV spike glycoprotein, 6LU7 COVID-19 3clpro/Mpro, 6VXX SARS-CoV-2 spike glycoprotein, 6VW1 SARS-CoV-2 chimeric receptor-binding domain. ${ }^{9-12}$ Structures of selected targets were downloaded from RCSB database

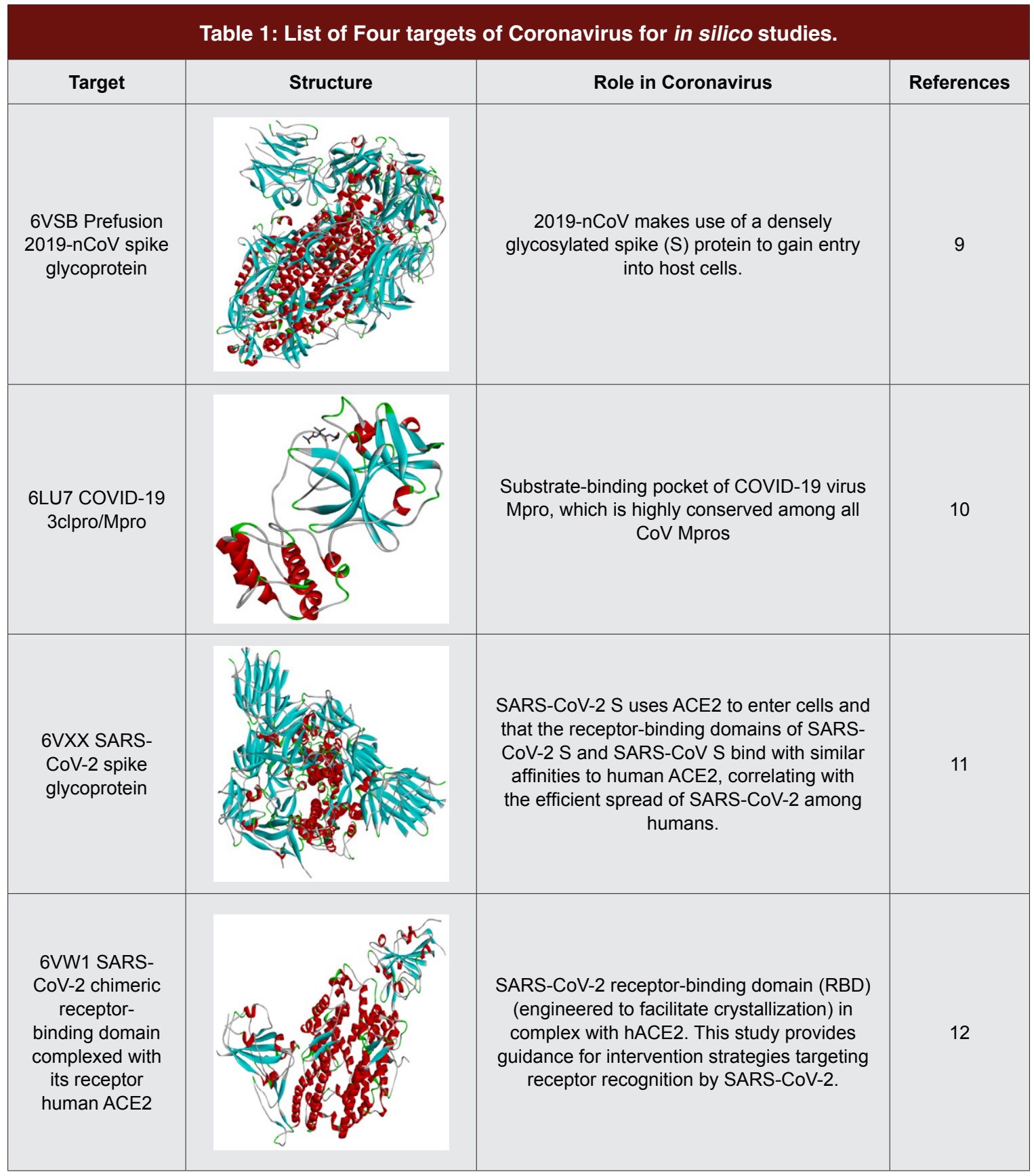


(www. rcsb.org). Subsequently structure of targets were optimized with Discovery studio and finalized for docking studies using Autodock Tool.

\section{Ligand (Phytocompound) selection and Preparation}

This study has incorporated eight phytocompounds from Nigella sativa which has been proven for their significant antiviral potential (Table 2). Their 3D structure was downloaded from PubChem database and used for assessing their inhibitory potential against all the four selected targets of coronavirus.

\section{Docking (Manual Docking) Analysis using AutoDock 4.2 software}

Inhibitory potential of all selected phytocompounds against these potential targets was evaluated by calculating binding energy obtained from AutoDock 4.2 as described by Pandey et al. 2019. ${ }^{13}$ Further ligand binding interaction was also identified using Discovery Tool and AutoDock tool in the target protein.

\section{Docking Analysis using online server (PatchDock)}

To further validate manual docking analysis, we have used an online server that can be freely accessed (http://bioinfo3d.cs.tau.ac.il/PatchDock/). PatchDock server is based on several algorithms such as geometry based docking. Selected phytocompounds of Nigella sativa were docked with all four different targets selected in this study.

\section{Drug Likeliness Filters}

We have selected four specific filters including Lipinski (Pfizer) filter, Ghose Filter, Veber Filter, Egan (Pharmacia) Filter, Muegge (Bayer) Filter for the elucidation of drug likeliness criteria of phytocompounds of Nigella sativa. ${ }^{14-19}$ Screened phyto compounds have fulfilled the Lipinski's criteria which consists of four parameters such as molecular mass (less than 500 daltons), $\mathrm{H}$ (Hydrogen) bond acceptor $(<=10), \mathrm{H}$ (hydrogen) bond donor $(<=5), \log \mathrm{P}$ $<=5$ (octanol- $\mathrm{H}_{2} \mathrm{O}$ partition coefficient). Selected compounds having 3 or more than 3 violations are not accepted as they do not follow the drug likeliness criteria. Criteria in ghose filter comprise of molecular weight (ranges from 160 to 480), atom count (ranges from 20 to 70), $\log \mathrm{P}$ (ranges from -0.4 to +5.6 ) and molar refractivity (ranges from 40 to 130). Criteria in Veber filter comprise of parameters including rotatable bonds $(<=10)$, Topological polar surface area $(<=140)$. Criteria in muegge filter comprise of number of Rigid bonds $(>=18)$, Rings $(>=3)$ and Rotatable bonds $(>=6)$.

\section{RESULTS}

\section{Screening of phytocompounds from Nigella Sativa for docking}

To discover a potent lead phytocompound for COVID-19 treatment, we have chosen eight potential phytocompounds from Nigella sativa which have displayed momentous inhibitory potential against numerous viral diseases such as Hepatitis, HIV and other viral diseases via inhibiting the activities of crucial enzymes including DNA polymerase, reversetranscriptase and protease inhibition, etc. [Table 2] depicts the list of phytocompounds from Nigella sativa with their reported antiviral efficacy for docking analysis against four different targets of coronavirus. Also we have chosen two standard drugs that are Abacavir and hydroxychloroquine in this study due to their reported role in COVID-19 treatment. ${ }^{20,21}$

\section{Molecular Docking using manual software (AutoDock 4.2)}

We have analyzed the ligand (Phytocompounds of Nigella sativa) receptor (four different targets of coronavirus) interaction by using a molecular docking tool AutoDock tool 4.2. Our results revealed that out of eight selected phytocompounds, Nigellone have shown the best binding efficacy against all the four targets of Coronavirus [Table 3, Figure 1].

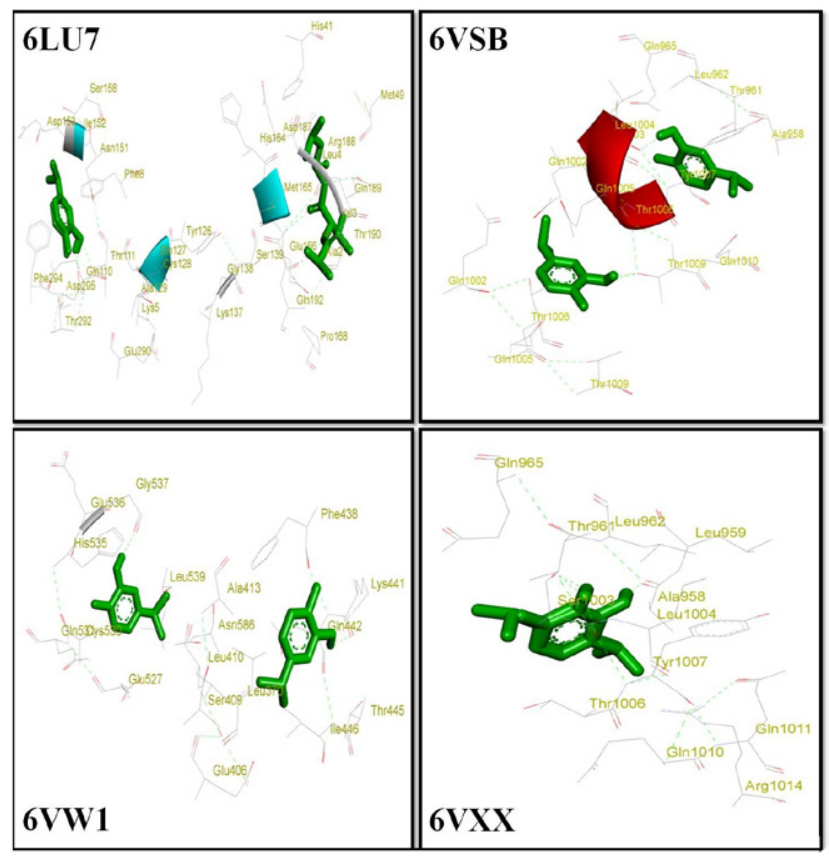

Figure 1: Docking Analysis (using AutoDock) of eight phytocompounds of Nigella sativa and two standard drugs with four different targets of Coronavirus. (A) Carvacrol (B) Nigellone (C) Nigellicine (D) Nigellidine (E) Nigellimine (F) Thymohydroquinone (G) Thymol $(\mathrm{H})$ Thymoquinonone (I) Remdesivir and $(\mathrm{J})$ Hydroxychloroquine. 
Table 2: List of selected phytocompounds of Nigella sativa for docking analysis.

\begin{tabular}{|c|c|c|c|}
\hline Compound & Pubchem ID & Structure & $\begin{array}{l}\text { Antiviral Efficacy } \\
\text { [References] }\end{array}$ \\
\hline Carvacrol & 10364 & & $27-31$ \\
\hline Nigellone (Dithymoquinone) & 398941 & & $32-34$ \\
\hline Nigellicine & 11402337 & & $32-35$ \\
\hline Nigellidine & 136828302 & & $32-35$ \\
\hline Nigellimine & 20725 & & $32-37$ \\
\hline Thymohydroquinone & 95779 & & $32-37$ \\
\hline Thymol & 6989 & & \\
\hline Thymoquinonone & 10281 & & $32-37$ \\
\hline
\end{tabular}




\section{Docking using online software PatchDock}

Patchdock (online server) was used to perform docking analysis to further validate the docking results obtained by AutoDock. PatchDock analysis also confirmed the better efficacy of Nigellone amongst all eight compounds of Nigella sativa. Nigellone has exhibited the best ligand receptor interaction with highest Ace value and patch dock score in comparison to other phytocompounds and selected standard drugs (Remdesivir and hydroxychloroquine).

\section{Drug likeliness criteria for phytocompounds of Nigella sativa}

Four different filters (Lipinski, Ghose, Veber, Muegge and Egan Filter) were utilized for assessing the drug likeliness criteria of all selected phytocompounds of Nigella sativa. Nigellone has followed drug likeliness criteria with no violation [Table 4]. However, out of the eight compounds, carvacrol has shown two violations, Thymohydroquinone has shown one violation, Thymol has shown two violations and Thymoquinonone has shown one violation [Table 4].

\section{Analysis of the inhibitory potential of phytocompounds with two standard drug Remdesivir and hydroxychloroquine}

Drug repurposing has been shown a new path towards the elucidation of inhibitory molecule for drug development against coronavirus in a time effective manner. Our study has also focused on exploring the potential of established drug for the viral diseases. In silico experimental findings in this study have clearly revealed the strong binding potential of Nigellone in comparison to two standard drugs Remdesivir and hydroxychloroquine [Table 3 and Table 5].

\section{DISCUSSION}

COVID-19 has presented major threat (to health and wealth) globally and no promising drug has been elucidated against this deadly disease. Natural compounds have exhibited significant medicinal benefits against numerous ailments such as neurological disorders, cancer, gastrointestinal disorders and other inflammatory diseases. ${ }^{22-26}$ Therefore we have designed this study to utilize the potential of phytocompounds and in silico techniques for finding a potent drug molecule which could not only prevent the pathogenesis of this virus (CoV 2019) but also helps in enhancing the body immunity. In silico techniques are safe and cost effective method for the elucidation of drug targets as well as their inhibitors. Nigella sativa (Black seed) has shown potential benefits for the treatment of numerous disorders such as bronchitis, asthma, swine flu, cough and several gastrointestinal disorders. Therefore we have selected eight potent phytocompounds of this plant for drug repurposing against coronavirus [Table 2].

\begin{tabular}{|c|c|c|c|c|}
\hline Compound & $\begin{array}{c}\text { Binding Affinity } \\
\text { (Kcal/mol) } \\
6 \text { LU7 }\end{array}$ & $\begin{array}{c}\text { Binding Affinity (Kcal/ } \\
\text { mol) } \\
6 \mathrm{VSB}\end{array}$ & $\begin{array}{c}\text { Binding Affinity } \\
\text { (Kcal/mol) } \\
\text { 6VW1 }\end{array}$ & $\begin{array}{c}\text { Binding Affinity (Kcal/ } \\
\text { mol) } \\
6 \mathrm{VXX}\end{array}$ \\
\hline Carvacrol & -4.37 & -4.59 & -4.56 & -4.8 \\
\hline Nigellone (Dithymoquinone) & -5.48 & -5.89 & -7.14 & -6.97 \\
\hline Nigellicine & -4.96 & -5.3 & -4.8 & -5.29 \\
\hline Nigellidine & -5.88 & -5.88 & -5.98 & -6.01 \\
\hline Nigellimine & -5.18 & -4.85 & -5.1 & -5.02 \\
\hline Thymohydroquinone & -4.3 & -4.51 & -4.39 & -4.51 \\
\hline Thymol & -4.53 & -4.41 & -4.31 & -4.87 \\
\hline Thymoquinonone & -4.6 & -4.51 & -4.58 & -5.13 \\
\hline Remdesivir & -1.96 & -4.09 & 16.82 & -1.94 \\
\hline Hydroxychloroquine & -4.13 & -3.61 & -4.83 & -3.95 \\
\hline
\end{tabular}

Comparative binding energies of eight phytocompounds of Nigella sativa and two standard drugs with four different targets of coronavirus using manual docking software AutoDock. (A): Comparative analysis of molecular docking analysis of antiviral compounds against four different targets of Coronavirus. (B) Molecular docking analysis of antiviral compounds against Prefusion 2019-nCoV spike glycoprotein with a single receptor-binding domain up (6VSB). (C): Molecular docking analysis of antiviral compounds against COVID-19 main protease in complex with an inhibitor $\mathrm{N}_{3}$ (6LU7). (D): Molecular docking analysis of antiviral compounds against SARSCoV-2 chimeric receptor r-binding domain complexed with its receptor human ACE2 (6VW1). (E): Molecular docking analysis of antiviral compounds against SARSCoV-2 spike glycoprotein (closed state) (6VXX). 
We have identified four different targets in our study including COVID-19 3clpro/Mpro, Prefusion 2019-nCoV spike glycoprotein, SARS-CoV-2 spike glycoprotein and SARS-CoV-2 chimeric receptorbinding domain complexes with its receptor human ACE2 [Table 1]. Mpro (Coronavirus main protease) has been involved with replication and transcription of coronavirus thereby presenting it as an attractive target for in silico studies. Perfusion 2019-nCoV spike glycoprotein helps the coronavirus in gaining entry into the host cell.

Another target naming SARS-CoV-2 chimeric receptorbinding domain complexed with its receptor human ACE2 stabilizes the viral binding to host cell. To gain entry into host cells, SARS-CoV-2 spike glycoprotein target has been associated with the spreading of

\begin{tabular}{|c|c|c|c|c|c|c|c|}
\hline Compound & Canonical Smile & $\begin{array}{l}\text { Lipinski } \\
\text { Filter }\end{array}$ & $\begin{array}{l}\text { Ghose } \\
\text { Filter }\end{array}$ & $\begin{array}{l}\text { Veber } \\
\text { Filter }\end{array}$ & $\begin{array}{l}\text { Egan } \\
\text { Filter }\end{array}$ & $\begin{array}{l}\text { Muegge } \\
\text { Filter }\end{array}$ & $\begin{array}{c}\text { Bioavailability } \\
\text { Score }\end{array}$ \\
\hline Carvacrol & $\mathrm{CC} 1=\mathrm{C}(\mathrm{C}=\mathrm{C}(\mathrm{C}=\mathrm{C} 1) \mathrm{C}(\mathrm{C}) \mathrm{C}) \mathrm{O}$ & Yes & $\begin{array}{l}\text { Yes } \\
(n=1)\end{array}$ & Yes & Yes & $\begin{array}{c}\text { Yes } \\
(n=2)\end{array}$ & 0.55 \\
\hline Nigellone & $\begin{array}{c}\mathrm{CC}(\mathrm{C}) \mathrm{C} 1=\mathrm{CC}(=\mathrm{O}) \mathrm{C} 2(\mathrm{C}(\mathrm{C} 1=\mathrm{O}) \\
\mathrm{C} 3(\mathrm{C} 2 \mathrm{C}(=\mathrm{O}) \mathrm{C}(=\mathrm{CC} 3=\mathrm{O}) \mathrm{C}(\mathrm{C}) \mathrm{C}) \\
\mathrm{C}) \mathrm{C}\end{array}$ & Yes & Yes & Yes & Yes & Yes & 0.55 \\
\hline Nigellicine & $\begin{array}{c}\mathrm{CC} 1=\mathrm{CC}(=\mathrm{O}) \\
\mathrm{C} 2=\mathrm{C}(\mathrm{N} 3 \mathrm{CCCCN} 3 \mathrm{C} 2=\mathrm{C} 1) \mathrm{C}(=\mathrm{O}) \\
\mathrm{O}\end{array}$ & Yes & Yes & Yes & Yes & Yes & 0.56 \\
\hline Nigellidine & $\begin{array}{c}\mathrm{CC} 1=\mathrm{CC}(=\mathrm{O}) \\
\mathrm{C} 2=\mathrm{C}(\mathrm{N} 3 \mathrm{CCCCN} 3 \mathrm{C} 2=\mathrm{C} 1) \\
\mathrm{C} 4=\mathrm{CC}=\mathrm{C}(\mathrm{C}=\mathrm{C} 4) \mathrm{O}\end{array}$ & Yes & Yes & Yes & Yes & Yes & 0.55 \\
\hline Nigellimine & $\begin{array}{c}\mathrm{CC} 1=\mathrm{NC}=\mathrm{CC} 2=\mathrm{CC}(=\mathrm{C}(\mathrm{C}=\mathrm{C} 12) \\
\mathrm{OC}) \mathrm{OC}\end{array}$ & Yes & Yes & Yes & Yes & Yes & 0.55 \\
\hline Thymohydroquinone & $\mathrm{CC} 1=\mathrm{CC}(=\mathrm{C}(\mathrm{C}=\mathrm{C} 1 \mathrm{O}) \mathrm{C}(\mathrm{C}) \mathrm{C}) \mathrm{O}$ & Yes & Yes & Yes & Yes & No $(n=1)$ & 0.55 \\
\hline Thymol & $\mathrm{CC} 1=\mathrm{CC}(=\mathrm{C}(\mathrm{C}=\mathrm{C} 1) \mathrm{C}(\mathrm{C}) \mathrm{C}) \mathrm{O}$ & Yes & $\begin{array}{l}\text { No } \\
(n=1)\end{array}$ & Yes & Yes & No $(n=2)$ & 0.55 \\
\hline Thymoquinonone & 10281 & Yes & Yes & Yes & Yes & No $(n=1)$ & 0.55 \\
\hline
\end{tabular}

\begin{tabular}{|c|c|c|c|c|c|c|c|c|}
\hline \multirow{3}{*}{ Compound } & \multicolumn{8}{|c|}{ Targets in Coronavirus } \\
\hline & \multicolumn{2}{|c|}{ 6LU7 } & \multicolumn{2}{|c|}{ 6VSB } & \multicolumn{2}{|c|}{ 6VW1 } & \multicolumn{2}{|c|}{$6 \mathrm{VXX}$} \\
\hline & Score & $\begin{array}{c}\text { ACE } \\
\text { Value }\end{array}$ & Score & $\begin{array}{c}\text { ACE } \\
\text { Value }\end{array}$ & Score & $\begin{array}{c}\text { ACE } \\
\text { Value }\end{array}$ & Score & ACE Value \\
\hline Carvacrol & 2718 & -44.50 & 3508 & -75.35 & 3446 & -44.76 & 3630 & -185.07 \\
\hline Dithymoquinone & 4160 & -133.5 & 5536 & -266.82 & 5096 & -76.51 & 5232 & -62.09 \\
\hline Nigellicine & 3476 & -79.94 & 4420 & -141.48 & 4168 & -199.34 & 4308 & -127.29 \\
\hline Nigellidine & 4110 & -80.39 & 5102 & -194.83 & 5194 & -227.72 & 4900 & -206.82 \\
\hline Nigellimine & 3290 & -73.52 & 4086 & -120.16 & 3900 & -137.83 & 4206 & -106.03 \\
\hline Thymohydroquinone & 2740 & -111.98 & 3710 & -44.16 & 3444 & -47.42 & 3666 & -175.88 \\
\hline Thymol & 2714 & -117.26 & 3562 & -78.29 & 3458 & -81.44 & 3534 & -188.34 \\
\hline Thymoquinone & 2834 & -75.13 & 3622 & -129.42 & 3468 & -63.29 & 3582 & -172.37 \\
\hline Remdesivir & 5624 & -197.02 & 7826 & -255.98 & 7040 & -159.45 & 7816 & -273.99 \\
\hline Hydroxychloroquine & 4082 & -95.32 & 5456 & -219.80 & 4962 & -197.02 & 5550 & -180.21 \\
\hline
\end{tabular}


this disease among human. Therefore finding phytocompounds against all the selected four targets will not only provide inhibits the replication of virus but also prevents the spreading of this disease. Amongst all the eight compounds, Nigellone has presented significant binding affinity against all the four targets thereby proving it as a potent drug candidate against COVID-19 treatment [Table 3 and Table 5]. Nigellone has also demonstrated better binding affinity in comparison to the two standard drugs (Remdesivir and hydroxychloroquine) used in our study. Several reports have emphasized the immune-regulatory effects of $\mathrm{N}$. sativa on COVID-19 pandemic thus it can be considered as a potential alternate to remdesivir since Nigella sativa would not only cure the disease but would also help in the improvement of human immunity. ${ }^{35}$ Further in vitro studies are needed to validate its inhibitory potential against coronavirus pathogenesis.

\section{ACKNOWLEDGEMENT}

The authors thank the management of Noida Institute of Engineering and Technology for providing the facilities to carry out this study.

\section{CONFLICT OF INTEREST}

The authors declare no conflict of interest.

\section{ABBREVIATIONS}

CoVs: Coronavirus; ACE2: Angiotensin-converting enzyme 2; PAMP: Pathogen-associated molecular patterns; HIV: Human immuno Virus; SARS: Severe acute respiratory syndrome; WHO: World Health Organization; PLpro: papain like protease; Ub: Ubiquitin; TLR: Toll like receptors

\section{REFERENCES}

1. Novel CP. The epidemiological characteristics of an outbreak of 2019 novel coronavirus diseases (COVID-19) in China. Zhonghua Liu Xing Bing Xue Za Zhi= Zhonghua Liuxingbingxue Zazhi. 2020;41(2):145.

2. Marazuela M, Giustina A, Puig-Domingo M. Endocrine and metabolic aspects of the COVID-19 pandemic. Reviews in Endocrine and Metabolic Disorders. 2020;1-3.

3. Sohrabi C, Alsafi Z, O'Neill N, Khan M, Kerwan A, Al-Jabir A, et al. World Health Organization declares global emergency: A review of the 2019 novel coronavirus (COVID-19). International Journal of Surgery. 2020.

4. Catanzaro M, Fagiani F, Racchi M, Corsini E, Govoni S, Lanni C. Immune response in COVID-19: Addressing a pharmacological challenge by targeting pathways triggered by SARS-CoV-2. Signal Transduction and Targeted Therapy. 2020;5(1):1-0.

5. Bouchentouf S, Missoum N. Identification of Compounds from Nigella sativa as New Potential Inhibitors of 2019 Novel Coronasvirus (Covid-19): Molecular Docking Study. 2019.
6. Yimer EM, Tuem KB, Karim A, Ur-Rehman N, Anwar F. Nigella sativa L.(black cumin): a promising natural remedy for wide range of illnesses. EvidenceBased Complementary and Alternative Medicine. 2019.

7. Ahmad S, Abbasi HW, Shahid S, Gul S, Abbasi SW. Molecular Docking, Simulation and MM-PBSA Studies of Nigella sativa Compounds: A Computational Quest to identify Potential Natural Antiviral for COVID-19 Treatment. Journal of Biomolecular Structure and Dynamics. 2020(justaccepted);1-6.

8. Pandey P, Khan F. Novel Coronavirus Disease 2019 (COVID-19): Emerging Public health Challenge. International Journal of Leading Research Publication. 2020;1(2):1-3.

9. Wrapp D, Wang N, Corbett KS, Goldsmith JA, Hsieh CL, Abiona O, et al. Cryo-EM structure of the 2019-nCoV spike in the prefusion conformation. Science. 2020;367(6483):1260-3.

10. Walls AC, Park YJ, Tortorici MA, Wall A, McGuire AT, Veesler D. Structure, function and antigenicity of the SARS-CoV-2 spike glycoprotein. Cell. 2020.

11. Jin Z, Du X, Xu Y, Deng Y, Liu M, Zhao Y, et al. Structure of M pro from SARSCoV-2 and discovery of its inhibitors. Nature. 2020;1-5.

12. Shang J, Ye G, Shi K, Wan Y, Luo C, Aihara H, et al. Structural basis of receptor recognition by SARS-CoV-2. Nature. 2020;581(7807):221-4.

13. Khan F, Pandey P, Mishra R, Jha NK, Sharma S. An in silico study on plantderived inhibitors against a prognostic Biomarker, Jab1. International Journal of Research in Pharmaceutical Sciences. 2019;10(2):1058-61.

14. Lipinski CA. Lead-and drug-like compounds: The rule-of-five revolution. Drug Discovery Today: Technologies. 2004;1(4):337-41.

15. Lipinski CA, Lombardo F, Dominy BW, Feeney PJ. Experimental and computational approaches to estimate solubility and permeability in drug discovery and development settings. Advanced drug delivery reviews. 1997;23(1-3):3-25.

16. Ghose AK, Viswanadhan VN, Wendoloski JJ. A knowledge-based approach in designing combinatorial or medicinal chemistry libraries for drug discovery. 1. A qualitative and quantitative characterization of known drug databases. Journal of Combinatorial Chemistry. 1999;1(1):55-68.

17. Veber DF, Johnson SR, Cheng HY, Smith BR, Ward KW, Kopple KD. Molecular properties that influence the oral bioavailability of drug candidates. Journal of Medicinal Chemistry. 2002;45(12):2615-23.

18. Egan WJ, Merz KM, Baldwin JJ. Prediction of drug absorption using multivariate statistics. Journal of Medicinal Chemistry. 2000;43(21):3867-77.

19. Muegge I. PMF scoring revisited. Journal of Medicinal Chemistry. 2006;49(20):5895-902.

20. Blanco JL, Ambrosioni J, Garcia F, Martínez E, Soriano A, Mallolas J, et al. COVID-19 in patients with HIV: Clinical case series. The Lancet HIV. 2020;7(5):e314-6.

21. Gautret $P$, Lagier JC, Parola P, Meddeb L, Mailhe M, Doudier B, et al. Hydroxychloroquine and azithromycin as a treatment of COVID-19: results of an open-label non-randomized clinical trial. International Journal of Antimicrobial Agents. 2020;105949.

22. Pandey P, Bajpai P, Siddiqui MH, Sayyed U, Tiwari R, Shekh R, et al. Elucidation of the chemopreventive role of stigmasterol against Jab1 in Gall bladder carcinoma. Endocrine, Metabolic and Immune Disorders-Drug Targets (Formerly Current Drug Targets-Immune, Endocrine and Metabolic Disorders). 2019;19(6):826-37.

23. Pandey P, Sayyed U, Tiwari RK, Siddiqui MH, Pathak N, Bajpai P. Hesperidin induces ROS-mediated apoptosis along with cell cycle arrest at G2/M phase in human gall bladder carcinoma. Nutrition and Cancer. 2019;71(4):676-87.

24. Pandey P, Sayyed U, Tiwari R, Pathak N, Siddiqui MH, Bajpai P. Anticancer and apoptosis-inducing effects of curcumin against gall bladder carcinoma. International Journal of Research in Pharmaceutical Sciences. 2018;9(1):6877.

25. Khan F, Pandey P, Jha NK, Jafri A, Khan I. Antiproliferative effect of Moringa oleifera methanolic leaf extract by down-regulation of Notch signaling in DU145 prostate cancer cells. Gene Reports. 2020 Jun 1;19:100619.

26. Khan F, Pandey P, Ahmad V, Upadhyay TK. Moringa oleifera methanolic leaves extract induces apoptosis and G0/G1 cell cycle arrest via downregulation of Hedgehog Signaling Pathway in human prostate PC-3 cancer cells. Journal of Food Biochemistry. 2020;25:e13338.

27. Gilling DH, Kitajima M, Torrey JR, Bright KR. Antiviral efficacy and mechanisms of action of oregano essential oil and its primary component 
carvacrol against murine norovirus. Journal of Applied Microbiology. 2014;116(5):1149-63.

28. Kamalabadi M, Astani A, Nemati F. Anti-viral effect and mechanism of carvacrol on herpes simplex virus type 1. International Journal of Medical Laboratory. 2018;5(2):113-22.

29. Upadhyay A, Venkitanarayanan K. In vivo efficacy of trans-cinnamaldehyde, carvacrol and thymol in attenuating Listeria monocytogenes infection in a Galleria mellonella model. Journal of Natural Medicines. 2016;70(3):667-72.

30. Mediouni S, Jablonski JA, Tsuda S, Barsamian A, Kessing C, Richard A, et al. Oregano oil and its principal component carvacrol inhibit HIV-1 fusion into target cells. Journal of Virology. 2020.

31. Ma L, Yao L. Antiviral Effects of Plant-Derived Essential Oils and Their Components: An Updated Review. Molecules. 2020;25(11):2627.

32. Majeed A, Muhammad Z, Ahmad H, Hayat SS, Inayat N, Siyyar S. Nigella sativa L.: Uses in traditional and contemporary medicines: An overview. Acta Ecologica Sinica. 2020.
33. Rahman MT. Potential Benefits of Combination of Nigella sativa and Zn Supplements to Treat COVID-19. Journal of Herbal Medicine. 2020;100382.

34. Tutuncu S. Black Seed (Nigella Sativa) and Immunomodulatory Effect. International Journal of Veterinary and Animal Research. 2020;3(1):6-9. E-ISSN: 2651-3609.

35. Kulyar MF, Li R, Mehmood K, Waqas M, Li K, Li J. Potential influence of Nagella sativa (Black Cumin) in reinforcing immune system: A hope to decelerate the COVID-19 pandemic. Phytomedicine. 2020;s153277.

36. Majdalawieh AF, Fayyad MW. Immunomodulatory and anti-inflammatory action of Nigella sativa and thymoquinone: A comprehensive review. International Immunopharmacology. 2015;28(1):295-304.

37. Eid AM, Elmarzugi NA, Abu ALM, Sawafta MN, Daana HI. A Review on the Cosmeceutical and External Applications of Nigella sativa. Journal of Tropical Medicine. 2017.

\section{PICTORIAL ABSTRACT}

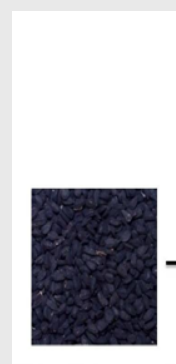

Dietary Phỵtocompounds of Nigella sativa

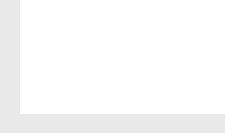

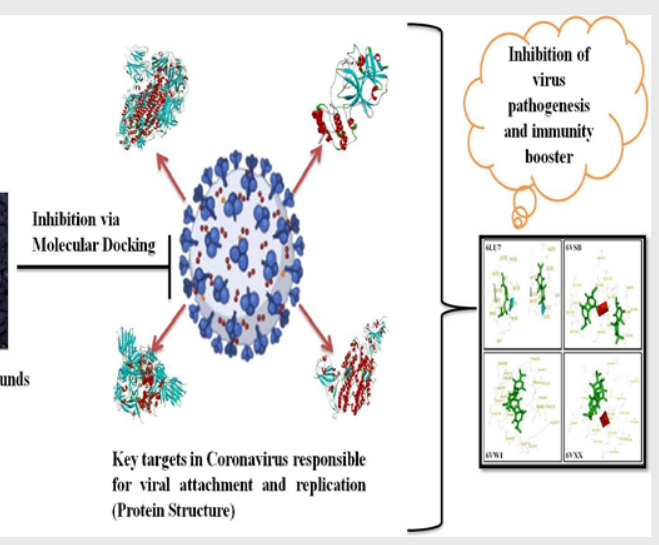

\section{SUMMARY}

This study focused on the concept of drug repurposing for finding more potent therapeutic option for COVID-19 management. We have elucidated nigellone as a potent phytocompound by utilizing several in silico techniques for drug development against coronavirus pathogenesis. Screened dietary phytocompound not only inhibits the replication and transcription of coronavirus but will also help in boosting up the immunity which could further leads to better management of this disease.

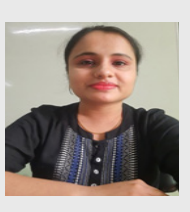

\section{About Authors}

Dr. Pratibha Pandey is an Assistant Professor working in the Department of Biotechnology at the Noida Institute of Engineering and Technology, Greater Noida, India. An ardent learner with Ph.D in Bioengineering (Biotechnology), M.Tech (Silver Medalist) (Biotechnology), MBA (HR) and B.Tech (Biotechnology) actively involved in research and development in the field of Biotechnology and Bioengineering. Awarded Young Women Scientist (WOS-A) with a project grant of 22 Lakhs from Department of Science and Technology, Government of India. Awarded Project grant of 3 Lakhs on the project under CRIP Programme of TEQIP III from AKTU, Lucknow. Her Research Area of Specialization includes Cancer Biology (Biomarkers and signalosomes in Gall bladder Cancer, Prostate cancer, Lung Cancer and Cervical cancer), Water Remediation, Chemoprevention using Natural Products via in silico and in vitro techniques.

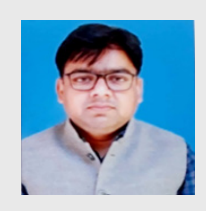

Dr. Fahad Khan is an Assistant Professor working in the Department of Biotechnology at the Noida Institute of Engineering and Technology, Greater Noida, India. Fahad's research investigates the effects of natural compounds against different types of cancers. His main focus is the cell signaling pathways by which the natural compounds could induce apoptosis in cancer cells and thus inhibits cancer metastasis and angiogenesis in in vitro models. He also has keen interest in computational biology based therapeutic approaches for disease prevention and exploration of underlying mechanism. Fahad's research findings have received extensive coverage in the national and international journal. He has published more than 15 research article in his last five years of research career. His work has been funded by Dr. APJ Abdul Kalam Technical University, Lucknow, India.

Cite this article: Pandey P, Khan F, Mazumder A, Rana AK, Srivastava Y. Inhibitory Potential of Dietary Phytocompounds of Nigella sativa Against Key Targets of Novel Coronavirus (COVID-19). Indian J of Pharmaceutical Education and Research. 2021;55(1):190-7. 